دراسة بعض التأثيرات الحيوية لبكتريا Enterococcus faecium كمعزز حيوي في افراخ الاجاج البياض 1- وزن الطير والتغيرات المرضية في الأكياس الهوائية و ألأمعاء عماد جواد خماس امجد حسين عليوي

$$
\text { فرع الامراض - كلية الطب البيطري - جامعة بغداد }
$$

لغرض معرفة تأثير بكتريا Enterococcus faecium كمعز حيوي في افراخ الدجاج البياض تم

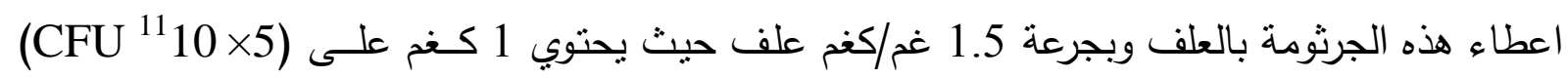

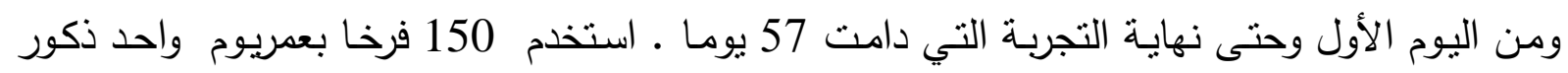

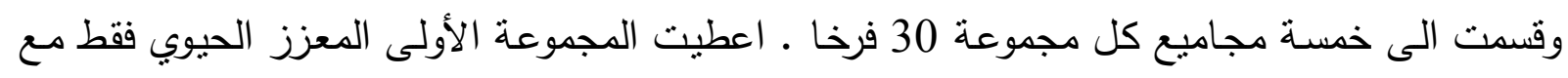
العلف واعطيت المجموعة الثانية المعزز الحيوي وعرضت الأفراخ الى جهد بيئي من حرارة عالية وقلئة

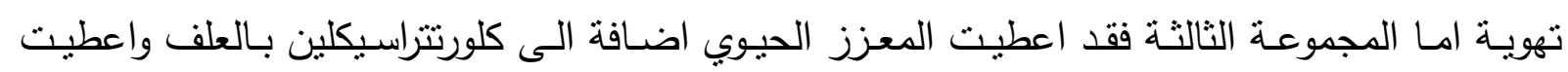

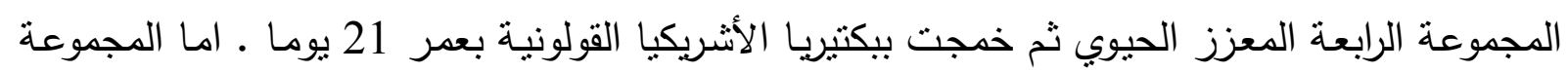
الخامسة فقد اعطيت علف اعنيادي وكمجموعة سيطرة. بينت النتائج ان اعطاء بكتيريا (Enterococcus faecium) كانت ذات أتأثير مهح معنويا في زيادة

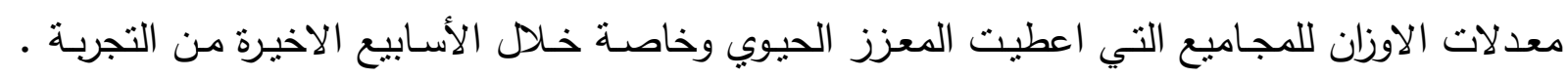

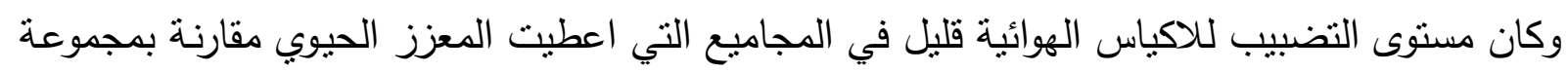

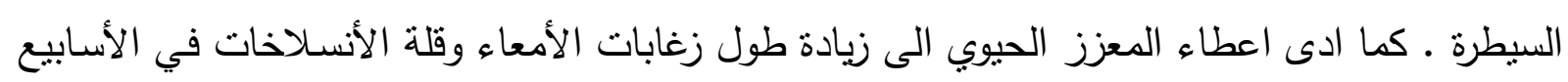

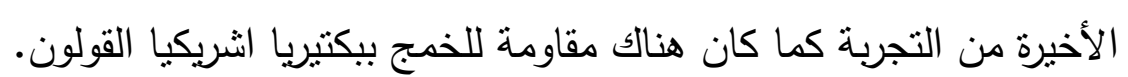

\title{
Study of some Impact Of Enterococcus faecium As Probiotic On Chick 1- Body Weight And Pathological Changes In Air Sacs And Intestine
}

Emad J.khamas and Amjad H.Elaywe

Dept. of pathology-college of Vet.Med-Baghdad university

\section{SUMMARY}

To investigate the impact of Enteococcus faecium as probiotic in layer chicks, this bacteria was given in feed at a dose rate of $1.5 \mathrm{gm}$ per $\mathrm{kg}$ feed, each $\mathrm{kg}$ of feed contained $5 \times 10^{11} \mathrm{cfu}$ along the period of the study (57 days). 150 one day old males were divided into five groups, 30 males each. The $1^{\text {st }}$ group was given the probiotic only in the feed, the $2^{\text {nd }}$ group was given the probiotic and exposed to high temperature and bad ventilation as a stress, and the third group was given the probiotic with chlortetracycline in feed while the fourth group was 
given the probiotic and then infected with $E$. coli on 21 day of age and the fifth group was given feed with out probiotic as the control group. The results showed that there was increase in body weight especially in the last weeks of the experiment. Turbidity of the air sacs was mild in the four group compared with control. Intestinal villi became elongated due to using of probiotic and there was less sloughing compared with control, and those groups showed resistance toward E. coli infection.

\section{المقدمة}

يعرف المعزز الحيوي(probiotic) بأنه احد المنتجات المصنعة والمتكونـة من احياء مجهريـة مفيدة

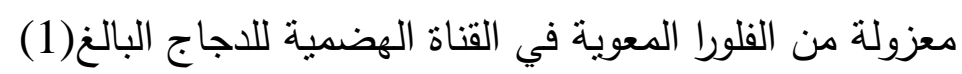

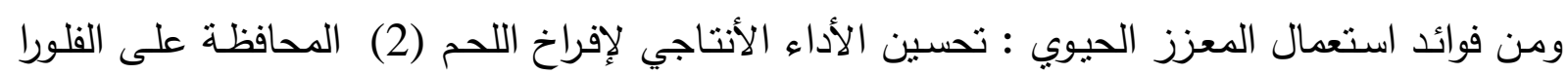

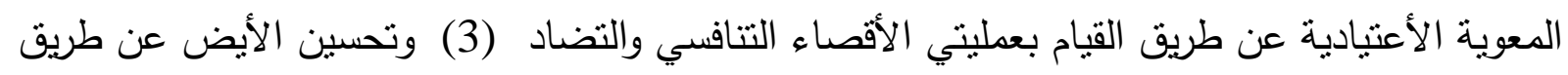

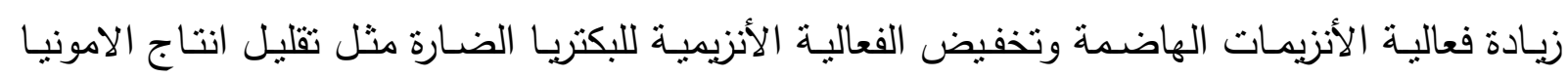

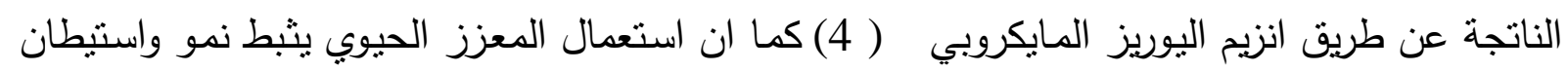

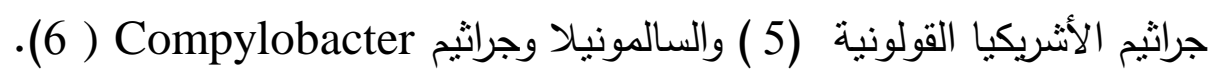
استهذف البحث دراسـة تأثير جراثيم Enterococcus faecium الدحضرة صناعيا على اوزان أفراخ

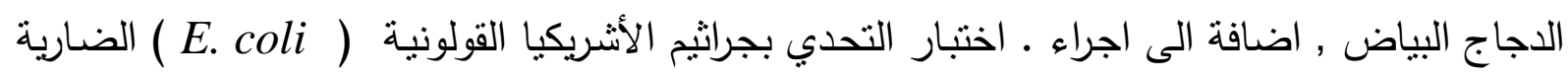
ودراسة مدى قدرة التعرض المايكروي المبكر بجراثيم Ent.faecium على جرائيم الاثريكيا القولونيـة وتأثيرها في الخمج بالمرض التتفسي المزمن كما استهدف البحث دراسة نسجية للأمعاء واحتمال تأثرها

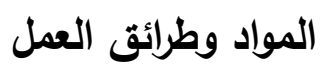

جلب 150 فرخ ذكور بياض (ISA BROWN)عمر يوم واحد وبمتوسط وزن 32.5 غم لكل فرخ من الثركة العراقية للإنتاج وتنويق اللحوم / الغالبية , وتمت التجربة في وحدة تجارب فرع الأمراض في كلية

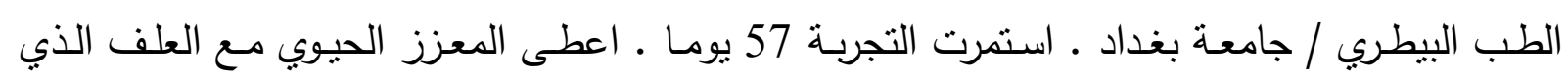
اعطى بصورة حرة ( ad libidum ) على طول فنزة التجربة.

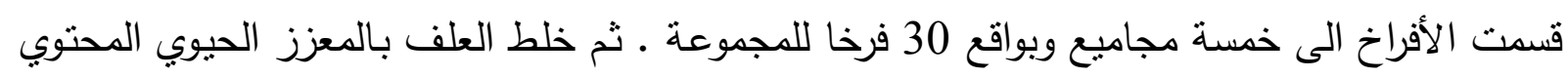
على ( Ent. faecium ) وبجرعة 1.5غ مع معزز لكل كغ علف . المجموعة الأولى اعطيت علف معامل بالمعزز على طول فنرة التجربة . 
المجموعة الثانية اعطيت علف معامل بالمعزز على طول فترة التجربة وعرضت الى جهذ بيئي حيث

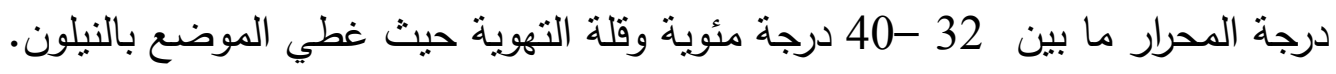

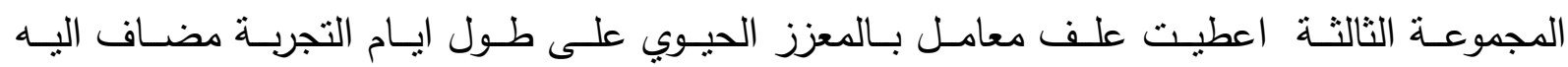
كلورتتراسايكلين بنسية غرام واحد لكل كغ علف .

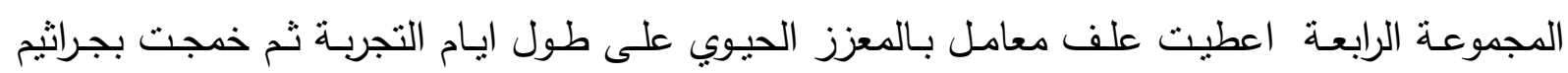
اشريكيا القولون بعمر 21 يوم عن طريق القصبة|لهوائيةمن خلال انيوب مطاطي شعري.

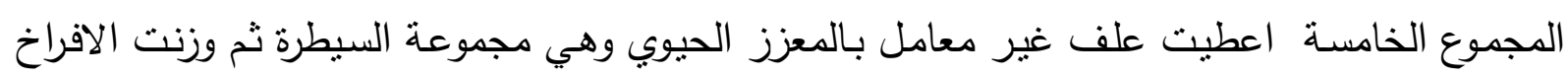

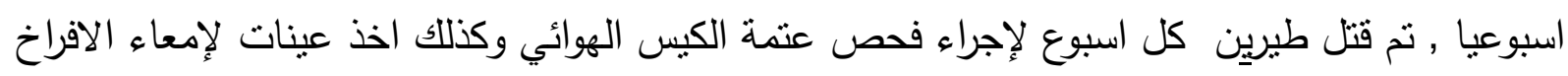

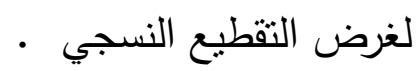

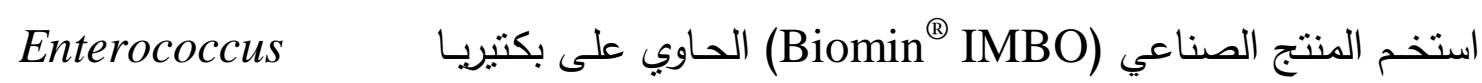
وبمعيار 5 × faecium

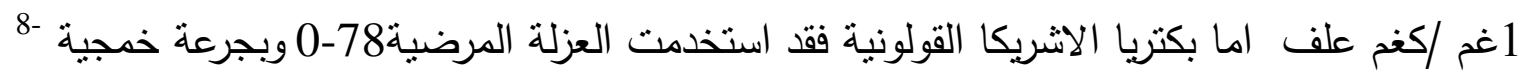
1.26×10 مل/وحدة مكونة للمستعمرات وحسب (7) وذللك لإجراء اختبار التحدي يوم 21 من التجربة التبنة حيث اعطي 0.1 مل عن طريق القصبة الهوائية .

\section{النتائج}

بينت نتائج معدل الأوزان للاسبوع الأول تفوقا معنويا للمجموعة الرابعة ( p p p.05) عن باقي المجاميع وبقيت هكذا حتى الأسبوع الرابع وكانت اقل قيمة للمجموعة الأولى وبفرق معنوي

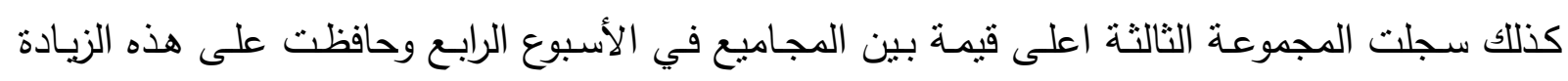

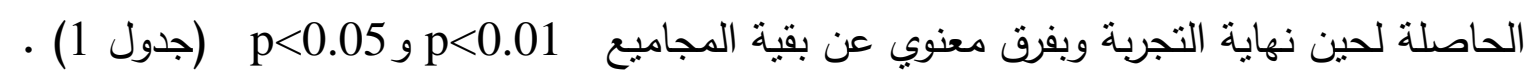

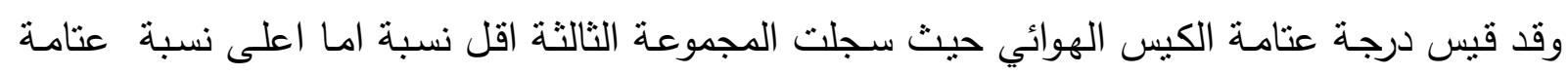

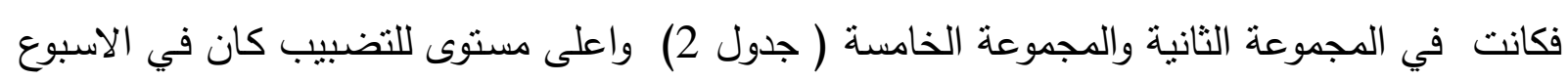
الثامن واقل مستوى في الاسبوع الرابع. جاءت نتائج الفحص النسيجي منماتلمة من حيث تأثير المجموعة والأسبوع حيث لوحظ في المجاميع

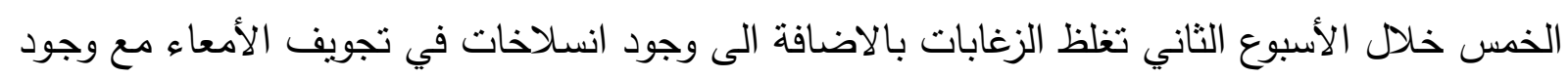

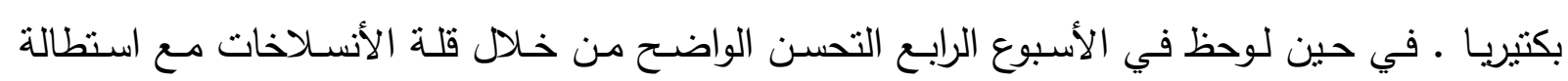
الزغابات وانعدام البكتيريا خاصة في المجموعة الثانية والثالثة في حين بقيت نفس الصني الصورة للأسبوع الثاني 
على المجاميع الأولى والرابعة والخامسة واستمرت هذه الصورة للمجموعة الخامسة الى الأسبوع السادس بينما تحسنت الصورة لبقية المجاميع من حيث استطالة الزغابات وقلة الانسلاخات وانعدام البكتيريا

جدول(1): معدل الأوزان (غم)

\begin{tabular}{|c|c|c|c|c|c|c|c|}
\hline \multicolumn{7}{|c|}{ المتوسطات 土 الخطأ القياسي } & \multirow[b]{2}{*}{ البحموعة } \\
\hline \multirow[t]{2}{*}{ مستوى المعنوية } & $\begin{array}{l}\text { مستوى المعنوية } 10.05<0 \\
(\mathrm{p}>05\end{array}$ & الخامسة & 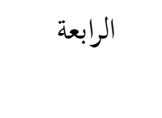 & 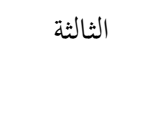 & الثانية & 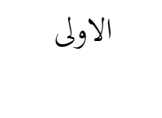 & \\
\hline & & & & & & & الأسبوع \\
\hline \multirow[t]{3}{*}{ NS } & * & 58.40 & 67.40 & 61.73 & 56.00 & 50.00 & الاول \\
\hline & & \pm 2.58 & \pm 4.86 & \pm 3.51 & \pm 3.53 & \pm 6.37 & \\
\hline & & $\mathrm{AB}$ & A & $\mathrm{AB}$ & $\mathrm{AB}$ & B & \\
\hline \multirow[t]{3}{*}{ NS } & * & 110.60 & 118.60 & 121.60 & 111.20 & 118.80 & الثاني \\
\hline & & \pm 9.17 & \pm 5.24 & \pm 6.60 & \pm 6.67 & \pm 5.34 & \\
\hline & & A & A & A & A & A & \\
\hline \multirow[t]{3}{*}{ NS } & * & 170.60 & 177.80 & 173.80 & 115.80 & 161.60 & الثالث \\
\hline & & \pm 5.91 & \pm 6.27 & \pm 3.96 & \pm 4.61 & \pm 9.14 & \\
\hline & & $\mathrm{AB}$ & A & $\mathrm{AB}$ & B & $\mathrm{AB}$ & \\
\hline \multirow[t]{3}{*}{ NS } & * & 243.40 & 257.20 & 280.00 & 244.20 & 262.80 & الرابع \\
\hline & & \pm 18.24 & \pm 11.23 & \pm 15.33 & \pm 5.07 & \pm 15.20 & \\
\hline & & A & $\mathrm{A}$ & A & A & A & \\
\hline \multirow[t]{3}{*}{ NS } & * & 323.20 & 334.60 & 364.40 & 312.80 & 324.60 & الخامس \\
\hline & & \pm 9.77 & \pm 30.79 & \pm 15.45 & $\pm \quad 6.25$ & $\pm \quad 9.35$ & \\
\hline & & $\mathrm{AB}$ & $\mathrm{AB}$ & A & B & $\mathrm{AB}$ & \\
\hline \multirow[t]{3}{*}{ *** } & * & 494.40 & 430.80 & 533.60 & 431.40 & 505.00 & السادس \\
\hline & & \pm 36.91 & \pm 29.34 & \pm 19.41 & \pm 18.77 & \pm 18.25 & \\
\hline & & $\mathrm{AB}$ & B & A & B & $\mathrm{AB}$ & \\
\hline \multirow[t]{3}{*}{ ** } & * & 605.60 & 562.60 & 648.80 & 537.60 & 614.40 & السابع \\
\hline & & \pm 6.85 & \pm 11.16 & \pm 5.39 & \pm 15.93 & \pm 13.47 & \\
\hline & & $\mathrm{B}$ & $\mathrm{C}$ & $\mathrm{A}$ & $\mathrm{C}$ & $\mathrm{B}$ & \\
\hline \multirow[t]{3}{*}{ *** } & * & 706.8 & 722.2 & 819.6 & 706.0 & 745.8 & الثامن \\
\hline & & $\pm \quad 37.78$ & \pm 17.37 & \pm 27.24 & \pm 22.20 & \pm 26.06 & \\
\hline & & B & B & A & B & $\mathrm{AB}$ & \\
\hline
\end{tabular}

- - الارقام تمتل المعدل الخطا القياسي

- - الحروف المختلفة تمثل وجود فرق معنوي (C,B,A) -

- - معدل القيم من الاعلى الى الاسفل حسب تسلسل الحروف (C,B,A) -

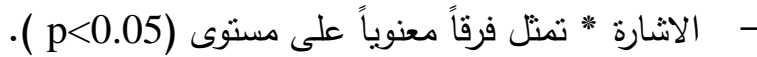

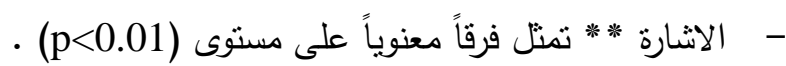

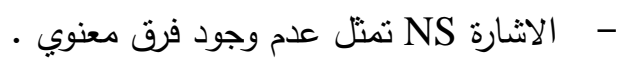


جدول(2): بيان فحص عتامة الكيس الهوائي

\begin{tabular}{|c|c|c|c|}
\hline الثامن & السادس & الرابع & بحموعة \\
\hline++ & ++ & + & الاولى \\
\hline++ & ++ & ++ & الثانية \\
\hline+ & - & - & الثالثة \\
\hline++ & + & + & الرابعة \\
\hline+ & ++ & ++ & الخنامسة \\
\hline
\end{tabular}

- مدم وجود عتامة

+

\section{المناقشّة}

ان المجاميع التي استخدمت المعزز الحيوي شهدت تحسن في معدل الوزن والتي سجلت فرقا معنويا

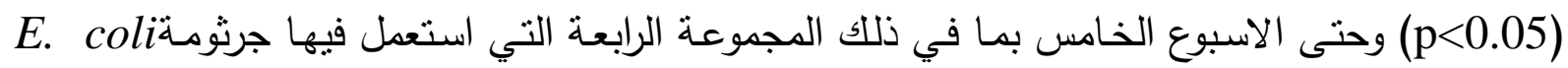

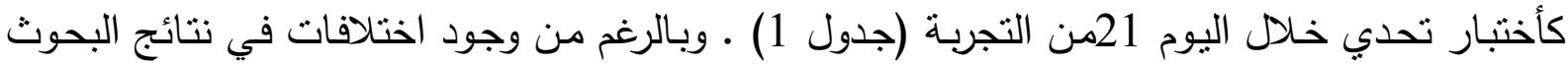

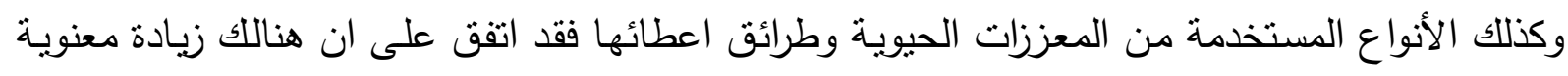

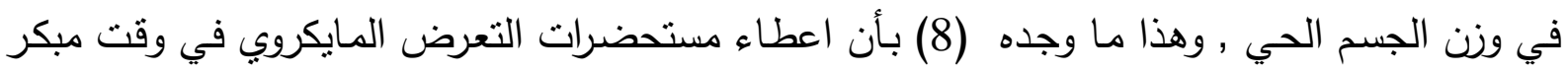

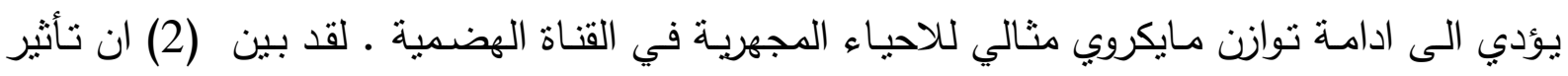

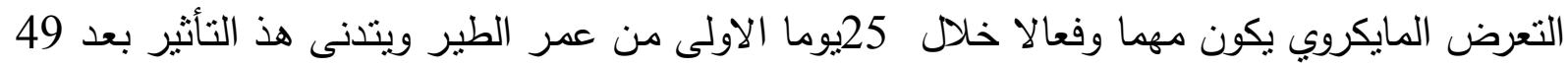
يوما وذلك بسبب استقرار الفلورا المعوية داخل القناة الهضمية ـ سجلت المجموعة الثالثة اعلى النتائج

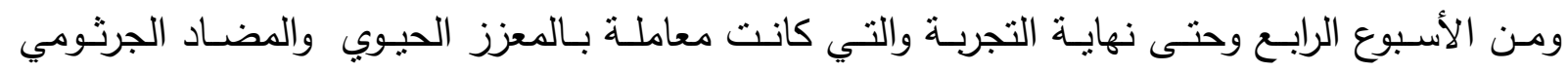

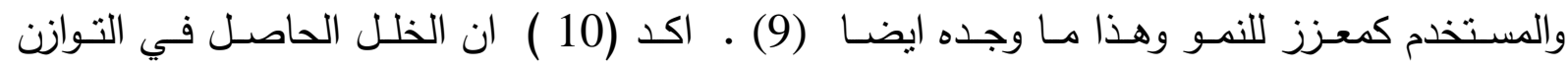

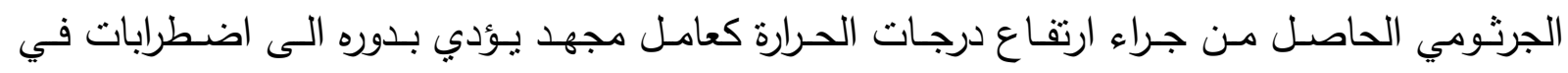

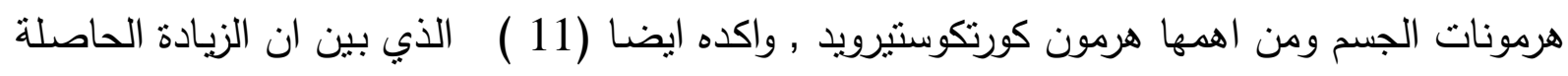

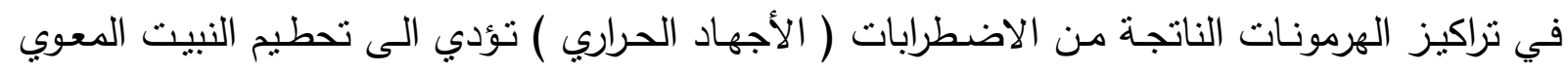

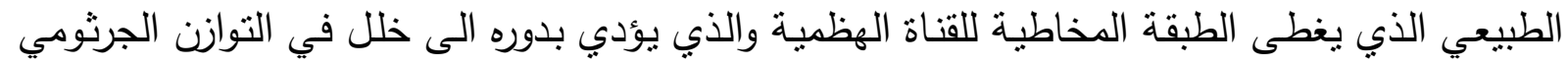

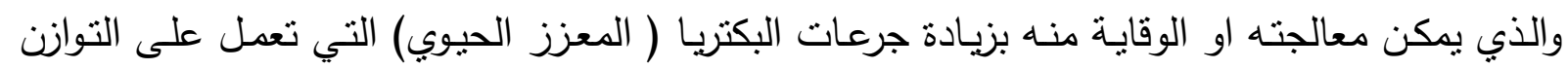
الميكروي وادامة النبيث المعوي. كانت المجموعة الثالثة هي اقل حالات عتامة للأكياس الهوائية عن باقي المجاميع وذللك لإن المجموعة

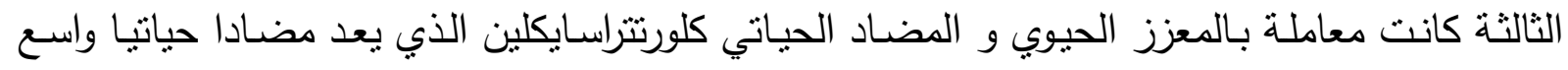


الطيف وله تأثثر في جرثومة الاشريكيا القولونية (12). وجاءت النتيجة هذه مطابقة لما جاء بـه (13)

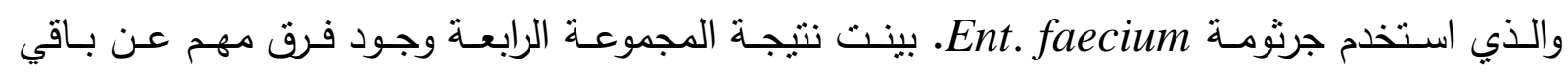

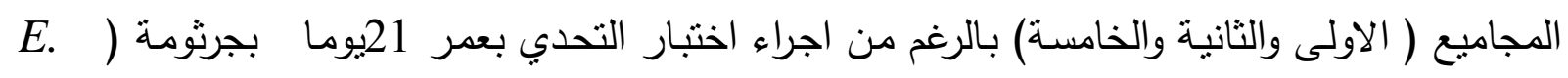

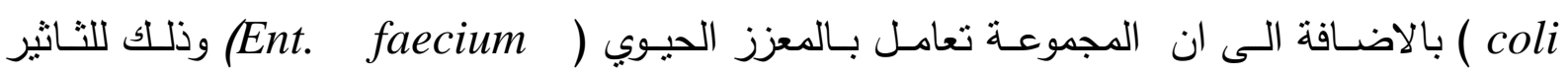

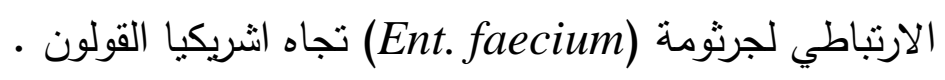

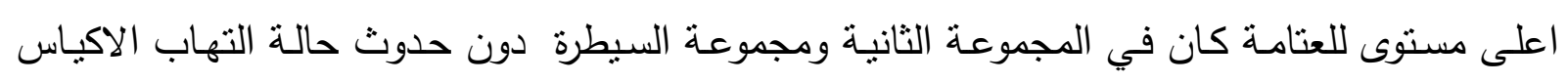

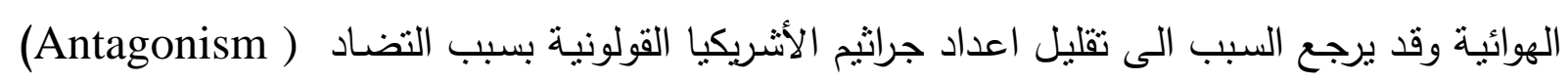

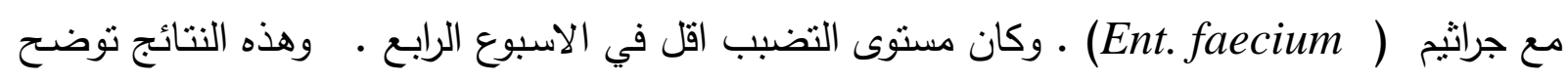

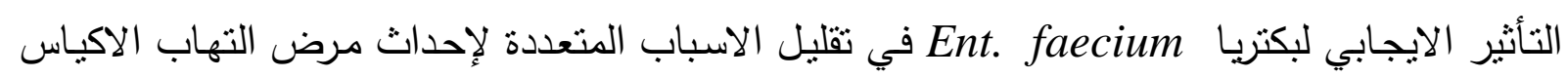

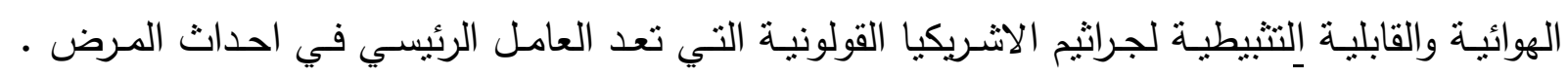

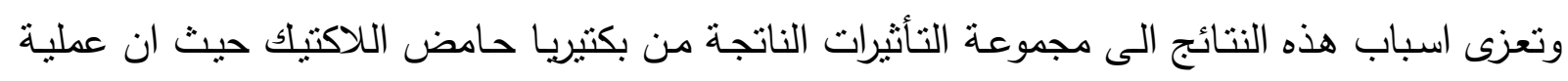
التثبيط ـ قد تعزى الى الانخفاض السريع في الاس الهيدروجيني وبالتالي الى تقليل نمو الجراثيم ولاسيما بكتيريا القولون (14) وجد (15 ) ان الزيادة في انتاج الحامض من بكتيريا حامض اللاكتيك سوف تلزيل

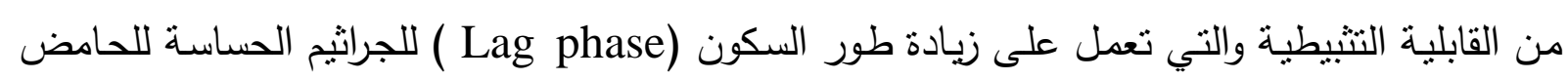

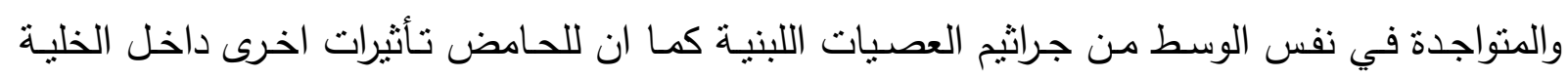

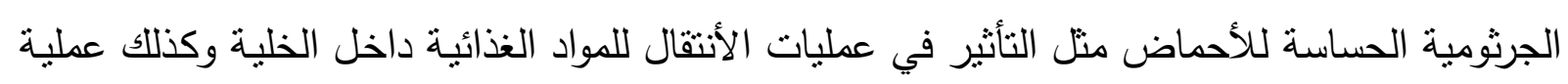
الفسفرة التأكسدية ( Oxidative phosphorelation ) فتعمل على تعطيلها ـ وقد تعمل ألية التتشيط

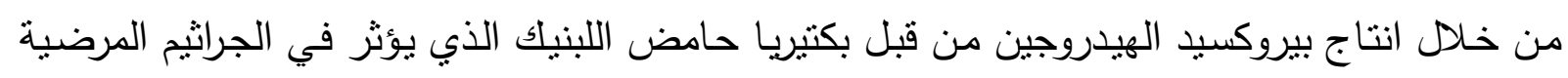
عن طريق فعله المؤكسد الثديد عليها او من خلال التأثنر المحطم للقواعد التركيبية الجزيئية لبروتينيات

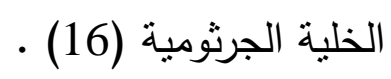
اما نأثير التعرض الميكروي في التكوين النسجي لبطانة الأمعاء فليس هناك تأثثر واضح للمعزز الحيوي

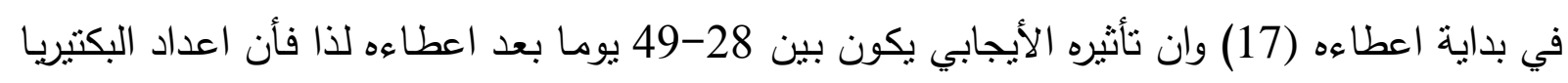

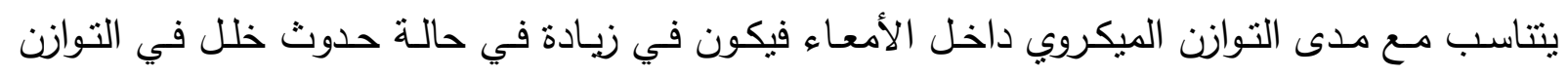

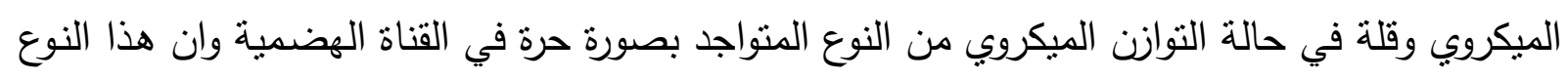

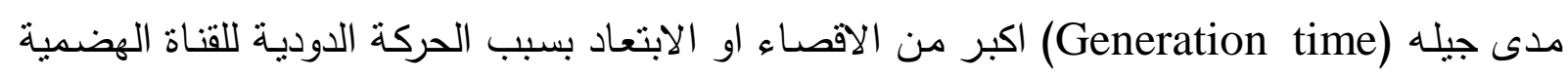

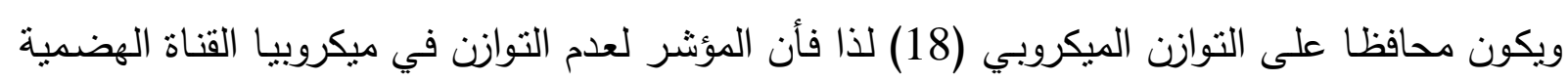

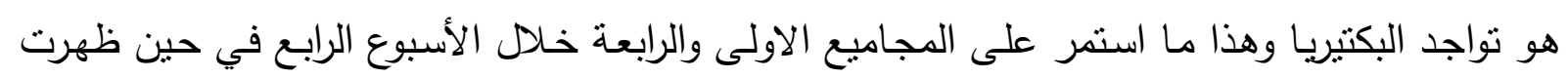

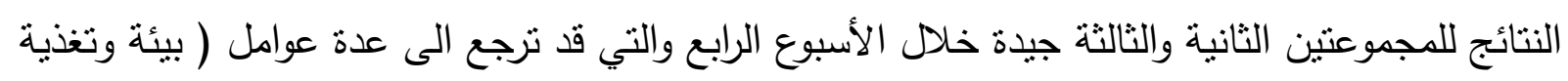


وميكروية ) التي اثاراليها (19) .اما نتائج الأسبوعين السادس والثامن فقد كانت مكونة من استطالة في

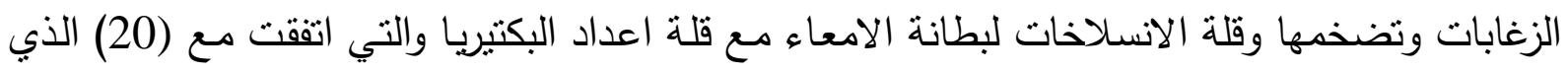
لاحظ عند اعطاء Leuteri يؤدي الى تحفيز المناعة غير النوعية ضد المسبيات المرضية مثل زيادة

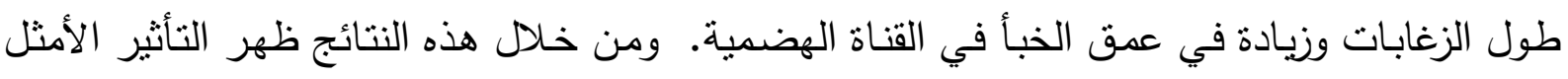

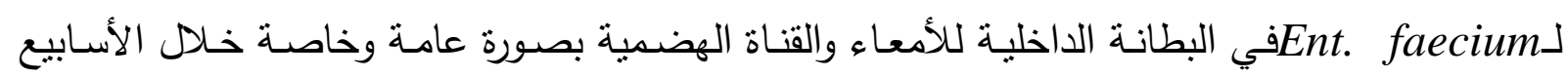

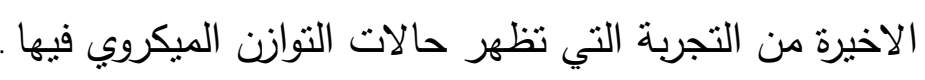

\section{المصادر}

1. Reuter G (2001) Probiotics: Possibilities and limitations of their application in food, animal feed, and in pharmaceutical preparations for man and animals Ber. Mun. Tier. Woch., 114 (11-17) : 410-419

2. Jin L Z,WHO W, Abdulah N and Jalaludin S( 1997). Probiotics in poultry: Modes of actions. World's Poultry Sci . J., 53:351-368 .

3. Jin, L Z, Ho Y W,.Ali A M, Abdulla N, and .Jalalaudin S,(1996b \} Effect of adherent lactobacillus spp . on invitro adherence of salmonella to the intestional epithelial cells of chickens . J. App1. Bacteriol., 81 : 206-221.

4. Jin L Z,.Ho W H,.Abdullah N and Jalaludin S, (1996a). Influence of dried

5. Bacillus subtilis and Lactobacilli cultures on intestinal microflora and performance in broiler Asian Australian J. of Anim. Sci. 9:397-404 (Cited by Jin et al., 1997)

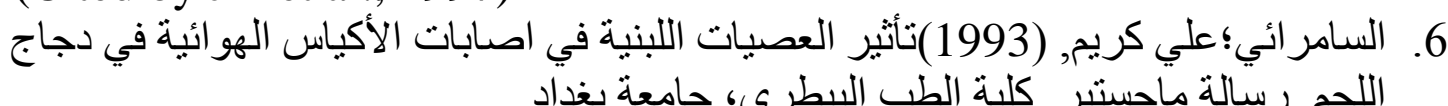

7. Line J E, Baily J S,.Cox N A, and Jstren N,(1997) Yeast treatment to reduce salmonella and campylobacter poulation Associated with broiler chickens subjected to transport stress . Poultry Sci., 76: 1227-1231 .

8. Qin Z R,.Fukata T,.Baba E, and Arakawa A,\{1995) Effect of lactase and lactobacillus acidophilus on the colonization of salmonella enteridis in chickes concurrently infected with Eiemerai tenella. Avian. Dis., 39: 548553.

9. Edens F W, Parkhurst C R, Cassas I A and Dobragasz W J, (1997) Principls of Ex- ovo competitive exclusion and in -ovo administration of Lactobacillus reuteri. Poultry Sci ., 76: 169-179

10.Owings, W J,Reynolds D L, Hasiak R J, and Ferket P R, (1990) Influence of dietary supplementation with streptococcus faecium M-74 on brioler body weight and intestinal microbial colonization . Poultry Sci., 69:12571264. 
11.Siegal H S, (1971) Adrenals stress and the environment. J. World pullt . sci ., 27:327-349

12.Leeson S, And Major D, (1990) as biotechnology gains monentum candian researchers study need for feed criteria. Feed Stuffs. (Cited by miles, 1998).

13.John H B, and Gross W B, (1997) Colibacillosis . In : Diseases of poultry . (ed by) Calnek, B.W.; H.J.Barnes; C.W. Beard; L.R. Mcdougald and Y.M. Salf. 10th Ed, Mosby-wolfe .p. 131-139.

14.Pantev A, Kabadjova P, Dalogalarrondo M. Haertle T,.Ivanoca I, Dousset X, Pervost H, and Chobert J M, (2002) Isolation and partial characterization of an antibacterial substance produce by Enterococcus faecium . Folia Microbiol , 47(4) 391-400. (Abstract).

15. Methner U, (2000) Administration of autochthonous intestinal microfloraA method to prevent salmonella infection in poultry. Dtsch. Tierarztl. Wochen. Schr, 107 (10): 402-408.

16.Tellez G, Peterone V M, Escorcia M, Morishita T Y, Cobb CF W, and Villasenor L, (2001) Evaluation of avian specific probiotic and S. Enteritidis, S. Typhimurium V.s. Heidelberg-specific antibodies on cecal colonization and organ invasion of S. enteritidis in broiler. J. Food Prot. 64(3) 287-291

17.Mead G C, (2000).Prospects for competitive exclusion treatment to control salmonellosis and other food borne pathogens in poultry. A review. Vet. J., 159 (2) 111-123.

18.Mohan K O.R, and Christoper R J,(1998) The role at ladobaallus sporogenes (probiotic) as feed additives Poultry Guide ., 25:37-40.

19.Miles R D, (1993) Manipulation of microflora of the gastrointestinal tract: Natural ways to prevent colonization by pathogens. pp. 133-150. In: Biotechnology in the feed industry. Proc. Alltech's 9th Ann. Symp. T.P. L yons ,ed ., Alltech's Technical . Publications, Nicholasville, KY.

20.Savage D C, (1991) Gastrointestinal microbial ecology ; possible mode of action of Direct-fed microbials in animal production-Areview of the literature . In : Direct-fed microbials in Animal production-Areview of the literature . PP 11-81. National feed ingredients Association, West Des Moines, IA, U.S.A.

21.Dunham H I, .Williams C, Edens F W, Cassas L A, and Dobrogosz.W S, (1993) .Lactobacillus reuteri immunomodulation of stressor-associated diseases in newly hatched chicken and turkey. Poultry Sci., 72(suppl.1): 308(Abstract). 